Bidirectional Associations between Affective Empathy and Proactive and Reactive Aggression By

(C) 2018

Elizabeth C. Tampke

B.A., University of Kansas, 2015

Submitted to the graduate degree program in Clinical Child Psychology and the Graduate Faculty of the University of Kansas in partial fulfillment of the requirements for the degree of Master of Arts

Chair: Paula Fite, Ph.D.

Ric Steele, Ph.D, ABPP

Eric Vernberg, Ph.D., ABPP

Date Defended: 3 December 2018 
The thesis committee for Elizabeth $\mathrm{C}$. Tampke certifies that this is the approved version of the following thesis:

\section{Bidirectional Associations between Affective Empathy and Proactive and Reactive Aggression}

Chair: Paula Fite, Ph.D.

Date Approved: 3 December 2018 
Abstract

Background: Preliminary evidence indicates that affective empathy is differentially associated with proactive and reactive functions of aggression, and anger dysregulation may impact these associations. However, more longitudinal research is needed to understand the bidirectional nature of these associations. Examining these potentially bidirectional associations in middle childhood may be particularly important, as this is when significant associations between empathy and aggression first start to become stable and more targeted interventions may be warranted.

Objectives: The current study examined the bidirectional associations between affective empathy and proactive and reactive aggression, as well as the moderating influence of anger dysregulation in middle childhood.

Methods: Data were collected from 294 elementary school children $\left(3^{\text {rd }}-5^{\text {th }}\right.$ graders $)$ and their teachers. Children self-reported on affective empathy and anger dysregulation and teachers reported on children's proactive and reactive aggression. Data were collected at two time points, approximately six months apart.

Results and Conclusions: As predicted, time 1 empathy was inversely associated with time 2 proactive aggression; however, contrary to expectations, time 1 proactive aggression trended towards being positively associated with time 2 empathy. Counter to expectations, time 1 empathy was not significantly association with time 2 reactive aggression; however, as predicted, time 1 reactive aggression was inversely associated with time 2 empathy. Finally, the expectation that anger dysregulation would moderate the links between reactive aggression and affective empathy was not supported. Results indicate that empathy is differentially associated with the functions of aggression over time. Findings and implications are discussed. 
Table of Contents

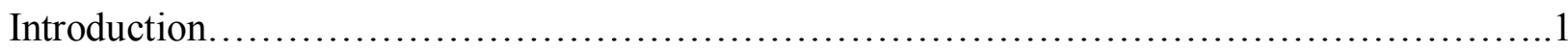

Empathy and Aggression.....................................................

Bidirectional Associations between Affective Empathy and Proactive Aggression........6

Bidirectional Associations between Affective Empathy and Reactive Aggression........9

The Role of Anger Dysregulation............................................11

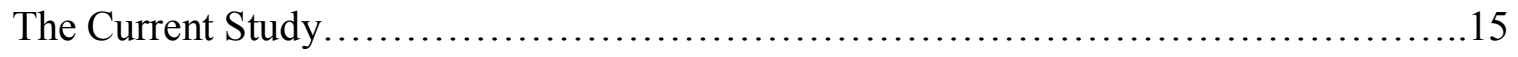

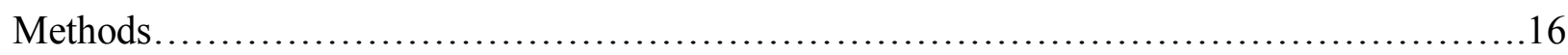

Measures..............................................................16

Procedures.................................................................

Data Analysis...........................................................20

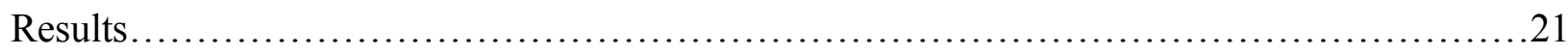

Descriptive Statistics...................................................21

First Order Effects.......................................................22

Anger Dysregulation Moderation..............................................23

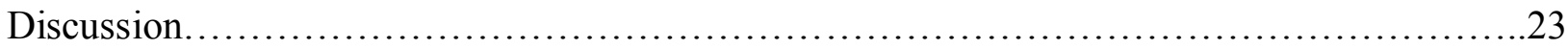

Bidirectional Associations between Affective Empathy and Proactive Aggression......23

Bidirectional Associations between Affective Empathy and Reactive Aggression.......25

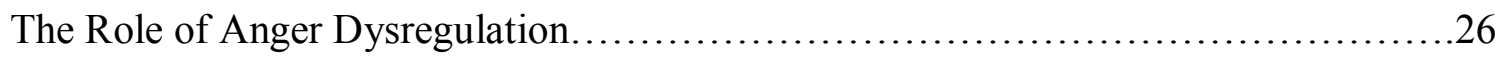

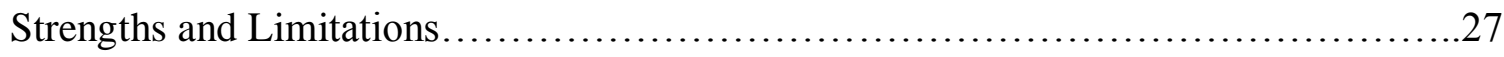

Clinical Implications..................................................... 28

References................................................................. 30

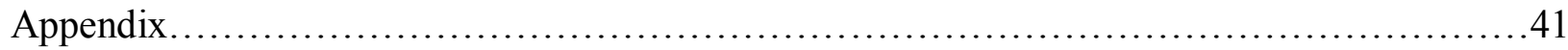


A robust amount of research has demonstrated that empathy and aggression are closely related constructs, with both concurrent and prospective studies supporting a link (Carlo, Mestre, Samper, Tur, \& Armenta, 2010; Euler, Steinlin, \& Stadler, 2017; Stavrinides, Georgiou, \& Theofanous, 2010). There is also preliminary experimental research suggesting the relationship may be causal rather than correlational in nature (for a review see Eisenberg, Eggum, \& Di Giunta, 2010). However, more research is needed to evaluate these associations in a bidirectional manner. In particular, research has used overly broad and inconsistent conceptualizations of both aggression and empathy (e.g., Konrath, O'Brien, \& Hsing, 2011; Lovett \& Sheffield, 2007) and lacked longitudinal studies examining how aggression and empathy mutually influence each other over time. It is important to note that aggression is a complex construct, composed of distinct functions (i.e., proactive and reactive), which differ in their underlying motivations, behavioral manifestations, and emotional reactivity (Bandura, 1983; Berkowitz, 1993; Dodge \& Coie, 1987). Moreover, preliminary evidence suggests that empathy may be differentially associated with proactive and reactive aggression (e.g., Euler et al., 2017; Stavrinides et al., 2010). Thus, examining the reciprocal relationship between empathy and distinct functions of aggression may be particularly important. Additionally, research on empathy and aggression is relatively sparse in middle childhood populations (Lovett \& Sheffield, 2007), which could be a critical period for development of both empathic and aggressive tendencies (Eisenberg et al., 2010; Eisenberg, Shea, Carlo, \& Knight, 1991; Piquero, Carriaga, Diamond, Kazemian, \& Farrington, 2012). A deeper understanding of the reciprocal relationships between proactive and reactive aggression and affective empathy in middle childhood could have important clinical implications, given the importance of this developmental period and that interventions focused on reducing aggression through empathy training have had mixed effects, possibly due to the 
type of empathy targeted and/or the specific function of aggression (e.g., Eisenberg et al., 2010; Espelage, Mebane, \& Adams, 2004; Malti, Chaparro, Zuffianò, \& Colasante, 2016). Given the limitations in the previous literature, the current study employs a short-term, longitudinal design to examine the bidirectional associations between affective empathy and proactive and reactive aggression in a middle childhood sample and evaluates the potential moderating effect of anger dysregulation.

\section{Empathy and Aggression}

Throughout the literature, definitions of empathy have been inconsistent, with researchers differing on the cognitive and emotional components that comprise the construct (Eisenberg et al., 2010; Konrath et al., 2011; Lovett \& Sheffield, 2007). In the current study, empathy is defined as understanding or experiencing an emotional state that is very similar to what another person may be feeling or expected to feel given the context (Eisenberg, Fabes, \& Spinrad, 2006; Eisenberg, Fabes, Schaller, Carlo, \& Miller, 1991; Hosking \& Walsh, 2005; Ickes, 1997; Jolliffe \& Farrington, 2006). While researchers differ on the complex constructs of empathy (e.g., Davis, 1980; Eisenberg et al., 2010; Jolliffe \& Farrington, 2006), empathy can be dichotomized into two forms: cognitive empathy and affective empathy (Decety \& Jackson, 2004; Eisenberg \& Eggum, 2009).

Cognitive empathy refers to the ability to objectively comprehend how someone would be expected to feel (Jolliffe \& Farrington, 2006) and includes being able to understand the perspective of someone else (i.e., perspective-taking; Davis, 1980). Perhaps not surprisingly, in the literature to date, cognitive empathy does not demonstrate a strong relationship with aggression (e.g., Eisenberg et al., 2010; Jolliffe \& Farrington, 2004; Stavrinides et al., 2010). This could be due to aggressive individuals "faking good" on cognitive empathy assessments or 
to the callous unemotional traits of aggressive individuals, which enable them to conceptually understand, but not care about, how another person is feeling (for a review see Eisenberg et al., 2010).

Affective empathy, on the other hand, refers to feeling the emotions (e.g., sorrow or distress) that someone would be expected to feel in a given situation (Jolliffe \& Farrington, 2006). Throughout the literature, affective empathy has also been referred to as empathic concern, sympathy, sympathetic concern, and dispositional sympathy (Davis, 1980; Eisenberg et al., 1991; Eisenberg et al., 1998; Eisenberg et al., 2010; Spinrad et al., 1999), with several studies using the same measure, but calling the construct by a different name (e.g., Davis, 1983; Eisenberg et al., 1991; Spinrad et al., 1999). Unlike cognitive empathy, affective empathy does demonstrate a strong inverse relationship with aggression (e.g., Carlo et al., 2010; Jolliffe \& Farrington, 2004) and inverse bidirectional associations between the two constructs have been found in a few studies (e.g., Stavrinides et al., 2010).

However, the nature of the relationship between affective empathy and aggression may be significantly different during distinct developmental periods, potentially due to differences in perspective taking and emotional maturity (for reviews see Eisenberg et al., 2010 and Lovett \& Sheffield, 2007). In a review of published literature on affective empathy and aggression, Lovett and Sheffield (2007) found that the relationship between aggression and affective empathy is unstable in early childhood (i.e., 3 to 7 year olds), with studies finding positive, negative, and null associations between affective empathy and aggression. However, the associations become more stable as youth enter middle childhood (i.e., 8-12 years old). The limited research conducted in this age group typically demonstrates a negative relationship between affective empathy and aggression (Lovett \& Sheffield, 2007). Further, the relationship becomes even more 
stable as youth mature, as evidenced by studies conducted in samples with youth ranging from 12 to 18 years old (Lovett \& Sheffield, 2007). However, there is relatively little research on how affective empathy and the specific functions of aggression reciprocally influence one another exclusively in middle childhood (i.e., 8 through 12 years old; for examples of existing studies see Carlo et al., 2010 and Stavrinides et al., 2010).

Several researchers have suggested that affective empathy and aggression are negatively related due to the inhibitory effects of affective empathy (Eisenberg et al., 2010; Hosking \& Walsh, 2005; Lovett \& Sheffield, 2007). Researchers propose the ability for individuals to experience others' emotional states impacts their behavior toward those individuals (Eisenberg et al., 2010); such that when individuals who typically aggress receive feedback on their victims' emotions (i.e., fear and sadness), these emotional cues produce an inhibition of aggression (Feshbach \& Feshbach, 1969; Mehrabian \& Epstein, 1972). In turn, individuals who experience low levels of affective empathy are more aggressive. In a review of the development of physical aggression (i.e., violence), Hosking and Walsh (2005) found that a key trait in the perpetrators of aggression (i.e., rapists, murders, wife batterers) is a lack of affective empathy, with more violent acts associated with greater lack in affective empathy. In a much less extreme example with adolescents in Spain, affective empathy negatively predicted physical and verbal aggression one year later (Carlo et. al, 2010).

Conversely, while this direction of the effect is substantially less studied, aggression may also influence empathy (e.g., Stavrinides et al., 2010). Empathy is a learned response which is typically first modeled to youth through their caregivers' response to the child's own distress (Hosking \& Walsh, 2005). Given that trait-level empathy and aggression both first begin to emerge around age 2 (for reviews see Eisenberg et al., 2010 and Piquero et al., 2012) and that 
caregivers can experience difficulty forming a positive bond with an aggressive child (Lorber, Del Vecchio, \& Slep, 2015), aggressive youth may have more difficulty eliciting empathic responses from their parents, and therefore, may have less opportunity to learn to respond empathically.

Moreover, the discrepancy between high aggression and low empathy may become further exacerbated as youth who either had less opportunity to develop empathy or were less receptive to empathy modeling continue to learn that aggressive behavior is adaptive and rewarding as they develop. The behavioral inhibition system/behavioral activation system (BIS/BAS) model of behavior (Gray, 1972) posits that individuals vary on their responsiveness to punishment and frustrated non-reward (i.e., BIS) and their responsiveness to reward and novelty (i.e., BAS). Therefore, youth who are highly sensitive to reward and novelty (i.e., BAS) and low on responsiveness to punishment (i.e., BIS) may find the positive results of their aggressive behavior particularly rewarding and any sort of negative consequence of their aggression, such as affective empathy with victims, easy to ignore or repress (e.g., Beaver, Lawrence, Passamonti, \& Calder, 2008; Harmon-Jones \& Peterson, 2008; Smits \& Kuppens, 2005). Moreover, aggressive individuals may be motivated to continue to repress or reduce feelings of empathy over time.

Alternatively, aggression in youth may also develop as a learned response to perpetually perceiving their environment as hostile and threatening via maladaptive social information processing (SIP; Choe, Shaw, \& Forbes, 2015; Crick \& Dodge, 1994, 1996; Dodge, 2006). Theoretically, this framework suggests that aggressive youth may be more likely to develop negative biases towards others (Crick \& Dodge, 1996; Dodge, 1980) and eventually seek to 
repress affective empathy responses. However, this link may differ based on the function of aggression (Dodge \& Coie, 1987).

\section{Bidirectional Associations between Affective Empathy and Proactive Aggression}

Proactive aggression is the controlled use of aggression in order to attain a goal (Dodge \& Coie, 1987) and can be explained by Bandura's (1973) social-cognitive learning theory, which suggests aggression is adopted by youth who find it adaptive (i.e., being aggressive gets me what I want). Additionally, proactive aggression aligns well with Gray's BAS/BIS (1972) model of behavior, in which individuals differ on their sensitivity to reward and punishment. Concerning proactive aggression, this model (and some evidence; e.g., Pederson, Fite, \& Bortolato, 2017) suggest that aggressive youth are likely highly sensitive to the rewards of aggression and less receptive to negative consequences of aggression. Therefore, proactively aggressive youth may be more likely to engage in aggression for its rewards, despite negative consequences to themselves as well as others.

Previous research and theoretical concepts suggest that affective empathy may significantly influence subsequent proactive aggression (Eisenberg et al., 2010; Mehrabian \& Epstein, 1972; Stavrinides et al., 2010). The controlled, planful nature of proactive of aggression suggests that potential aggressors have time to reflect on the positive and negative outcomes of their potential actions (e.g., attaining a goal vs. harming a victim) before they aggress (Bandura, 1973). On one hand, high levels of affective empathy may motivate youth to not engage in subsequent proactive aggression, as an individual who experiences high levels of affective empathy may be more likely to the experience negative emotions of their victim and this aversive experience may lead them to inhibit aggressive acts in the future (Decety \& Ickes, 2009; Decety \& Moriguchi, 2007). On the other hand, the opposite would also be true, such that a lack 
of affective empathy may lead to increased engagement in proactive aggression. An individual who experiences low levels of affective empathy would not be likely to experience affective congruence with their victims (i.e., negative emotions), however they would experience the rewards of proactive aggression (i.e., goal attainment). Therefore, lack of affective empathy may serve to further disinhibit potentially proactively aggressive youth. Previous research supports these inclinations, with a few studies in youth aged 11 to 18 years consistently demonstrating that affective empathy and proactive aggression are significantly negatively correlated with each other (e.g., Espelage et al., 2004; Euler et al., 2017) and longitudinal studies in early through middle childhood samples (i.e., 2 through 11 year olds) demonstrating low levels of affective empathy predicting increases in proactive aggression (Deschamps, Verhulp, de Castro, \& Matthys, 2018; Ostrov, Murray-Close, Godleski, \& Hart, 2013; Stavrinides et al., 2010). Moreover, other research has examined the predictive associations between factors associated with affective empathy (i.e., callous-unemotional traits) and proactive aggression. Callousunemotional traits (CU) characterize a lack of prosocial emotions, including low empathy and guilt, and have been identified in both middle childhood and adolescent samples (Frick, Cornell, Barry, Bodin, \& Dane, 2003; Kruh, Frick, \& Clements, 2005). Moreover, research has found that in youth aged 14 to 18 years $\mathrm{CU}$ traits positively predicted proactive aggression over time (e.g., Orue, Calvete, \& Gamez-Guadix, 2016).

Alternatively, high levels of proactive aggression may also impact affective empathy through aggressive youth learning to repress empathic responding. Following the BAS/BIS model, some youth may be particularly sensitive to the rewards of aggression and dulled to the negative consequences of aggression (Beaver et al., 2008; Gray, 1972; Harmon-Jones \& Peterson, 2008; Smits \& Kuppens, 2005). Therefore, as youth high on BAS and low on BIS learn 
to adopt aggressive tendencies, they may not be receptive to the "punishing" feelings that typically accompany the experience of affective empathy with victims of aggressive acts (e.g., guilt). Furthermore, over time the salience of the reinforcement of aggression may motivate proactively aggressive youth to repress feelings of affective empathy. Unfortunately, the potential influence of proactive aggression on affective empathy has been understudied. A correlational study by Katsuma and Yamasaki (2008) was identified which examined the influence of aggression on empathy in middle childhood (i.e., fourth through sixth graders) via structural equation modeling and found that proactive aggression was associated with fewer empathy responses (e.g., emotion sharing) in youth. Additionally, one longitudinal study demonstrated that proactive aggression is negatively associated with affective empathy (e.g., Stavrinides et al., 2010) in sixth grade youth. Finally, retrospective studies have found that proactive aggressors do not feel empathy for their victims in school age youth as well as adult samples (Fernandez \& Marshall, 2003; Olweus, 1993). However, it is important to note that the aggressors in the retrospective studies (i.e., Fernandez \& Marshall, 2003; Olweus, 1993) only lacked feelings of empathy for their specific victims; therefore, they may have learned to repress empathy specifically when it was adaptive to them. Conversely, they have also learned to have empathetic responses for other individuals.

The current study advances the research on empathy and proactive aggression through using a short-term longitudinal design and a middle childhood sample to assess the bidirectional associations between proactive aggression and affective empathy specifically. Longitudinal research designs to assess the associations between proactive aggression and empathy have been under-utilized in middle childhood populations. A longitudinal design allows us to better assess the reciprocal relationship between proactive aggression and affective empathy over time, which 
is especially important given the limited research on proactive aggression as a predictor of subsequent affective empathy. Furthermore, examining this effect in middle childhood, when the links between proactive aggression and affective empathy first become significant, will advance the limited research on this topic in this period of empathic and aggressive development. We expected bidirectional associations to emerge between affective empathy and proactive aggression, such that high levels of affective empathy would predict low levels of proactive aggression and high levels of proactive aggression would predict low levels of affective empathy over time.

\section{Bidirectional Associations between Affective Empathy and Reactive Aggression}

Reactive aggression is the impulsive use of aggression in response to a perceived threat (Dodge \& Coie, 1987) and can be explained by Berkowitz's (1993) frustration-aggression theory, which states that a barrier or threat to expected goal attainment instigates impulsive, emotional aggression. Like proactive aggression, reactive aggression is also a learned response. However, unlike proactive aggression, which suggests that aggression is learned as youth find it rewarding (Bandura, 1973; Gray, 1972), reactive aggression may be learned via maladaptive SIP (Crick \& Dodge, 1994, 1996; Dodge, 2006). Aligning with Berkowitz's (1993) frustrationaggression theory, SIP problems in childhood include a proclivity to attribute hostile or threatening intent to ambiguous situations and to react with aggression to perceived threats. Maladaptive SIP contributes to the learning of reactive aggression through the development of hostile schemas, which are embedded into memory through constant and repeated access to hostile representations and aggressive responses, which make reactively aggressive responses easily available in both threatening and innocuous situations (Dodge, 2006). 
Regarding the impact of affective empathy on reactive aggression, reactive aggression is impulsive and characterized by emotional over-arousal (Dodge \& Coie, 1987); therefore, it is likely that affective empathy would produce aggression inhibition, and it is also possible that affective empathy could prime aggressive impulses. The impulsivity of reactive aggression suggests that aggressive youth are unlikely to reflect on the consequences of their actions (i.e., the feelings of their victims) before aggressing. However, the likelihood of an individual engaging in reactive aggression is increased by the unpleasantness of an experience (Berkowitz, 1993), therefore individuals who experience affective empathy aversively (i.e., via personal distress or with negative emotions such as sadness or anger) may be more likely to aggress. Research on the relationship between affective empathy and reactive aggression is mixed, with studies demonstrating nonsignificant, positive, and negative relationships between the two constructs depending on the age and characteristics of the sample (Deschamps et al., 2018; Euler et al., 2017; Lovett \& Sheffield, 2007; Pouw, Rieffe, Oosterveld, Huskens, \& Stockmann, 2013). Euler and colleagues (2017) found that affective empathy was not associated with reactive aggression in a sample of highly aggressive adolescents (aged 12 to 18 years). Conversely, a study which examined both typically developing adolescents and adolescents with Autism Spectrum Disorder (ASD; aged approximately 9 to 15 years) found that while there was a negative relationship between affective empathy and reactive aggression in typically developing youth, there was a positive relationship between reactive aggression and affective empathy in youth with ASD (Pouw et al., 2013). On the other hand, other studies with typically developing youth (aged 2 through 7 years) have found positive and null relationships between affective empathy and reactive aggression (Deschamps et al., 2018; Lovett \& Sheffield, 2007). Some 
researchers have proposed that the differences in associations across studies may be due to population differences in emotion regulation (e.g., Lovett \& Sheffield, 2007; Pouw et al., 2013).

Regarding the influence of reactive aggression on affective empathy, the manner in which reactive aggression is learned and enforced makes it unclear whether and how reactive aggression would play a role in decreasing affective empathy over time. Unlike the relationship between proactive aggression and empathy, in which repressing feelings of empathy is adaptive for the continuation of rewarding aggressive behavior, reactive aggression is thought to develop defensively in response to maladaptive SIP, which characterizes ambiguous interactions as hostile and threatening (Dodge, 2006). Theoretically, it could be possible that as reactive aggression becomes embedded in one's cognitive schema and increasingly readily available as a response (Dodge, 2006), individuals may gradually develop universal negative perceptions of peers and gradually decline in their level of affective empathy. Unfortunately, research on the influence of reactive aggression on any form of empathy is limited, with the overwhelming majority of studies examining how empathy predicts reactive aggression (and not how reactive aggression predicts empathy). Only one study was identified which examined the influence of reactive aggression (and proactive aggression) on empathy in middle childhood youth (i.e. fourth through sixth graders; Katsuma \& Yamasaki, 2008). Using structural equation modeling, the study found a significant relationship between proactive aggression and empathy, but not reactive aggression. Based on the limited empirical evidence available, it is likely that high levels of affective empathy predict high levels of reactive aggression. It is also possible that high levels of reactive aggression may result in lower levels of empathy, but this association is less clear. Moreover, it is important to further examine these links and emotion regulation may need to be considered. 


\section{The Role of Anger Dysregulation}

Emotion regulation refers to the ability to moderate, evaluate, and modify emotional responses (Thompson, 1994). As Ostrov and colleagues (2013) point out, the core features of emotion regulation are a subject of substantial debate; however, generally, emotion regulation can be dichotomized into two main constructs: emotion regulation skills and dysregulated negative affect (Shields \& Cicchetti, 1997; Thompson, Lewis, \& Calkins, 2008; Zeman, Shipman, \& Penza-Clyve, 2001). Emotion regulation skills refer to the positive aspects of emotion regulation, which include modulating negative emotions (e.g., anger or sadness) in a way that is adaptive to the social context (Cooley \& Fite, 2016; Ostrov et al., 2013; Saarni, 1999). Dysregulated negative affect, on the other hand, refers to the inability of individuals to regulate negative emotions, such as anger, sadness, or worry (Cooley \& Fite, 2016; Ostrov et al., 2013; Shields \& Cicchetti, 1997). While research in middle childhood and adolescent youth have linked deficits in emotion regulation skills with aggression (Calvete \& Orue, 2012; de Castro, Merk, Koops, Veerman, \& Bosch, 2005), there is reason to believe that emotion dysregulation may play a particularly salient role in the associations between empathy and reactive and, to a lesser extent, proactive aggression (e.g., Marsee \& Frick, 2007; Ostrov et al., 2013).

More specifically, the construct of dysregulated anger may be especially important to examine when considering the bidirectional associations between affective empathy and reactive aggression (Calvete \& Orue, 2012; Marsee \& Frick, 2007; Ostrov et al., 2013). Unfortunately, there is a paucity of research on empathy and anger in youth, as articles examining the relationship between empathy and anger were not identified. However, research on anger and aggression is more developed. Specifically, evidence suggests that anger is differentially associated with proactive and reactive aggression, with nonverbal, physiological, and reported 
anger generally demonstrating positive associations with reactive aggression and mixed associations with proactive aggression (de Castro et al., 2005; Hubbard et al., 2002, 2004; Marsee \& Frick, 2007; Ostrov et al., 2013; Pouw et al., 2013). For example, a longitudinal study in an early childhood sample (i.e., ages 2 to 4 years old) found that teacher-reported trait anger predicted increases in both proactive and reactive aggression four months later; however, reactive aggression at time 1 predicted increases in anger and decreases in emotion regulation skills at time 2, while proactive aggression levels at time 1 predicted decreases in anger and increases in emotion regulation skills at time 2 (Ostrov et al., 2013).

Youth who experience affective empathy alongside emotion dysregulation, anger dysregulation specifically, may be more primed to engage in reactive aggression (Anderson \& Bushman, 2002; Berkowitz, 1993; Eisenberg et al., 2010). On the other hand, there is also reason to believe if reactive aggression influences affective empathy, anger dysregulation would moderate this link. Specifically, youth who are reactively aggressive may have adapted these tendencies in response to constant perceptions of the environment as threatening (Dodge, 2006); therefore, it is possible that anger dysregulation will exacerbate these negative perceptions and lead youth to have negative biases against their peers and, consequently, experience less affective empathy over time. Preliminary research supports the influential role of dysregulation in early childhood, middle childhood, and adolescent samples, suggesting that when positive associations between affective empathy and reactive aggression are found, it may be due to underlying anger dysregulation (Batson, 1991; Eisenberg et al., 2010; Lovett \& Sheffield, 2007; Pouw et al., 2013). Research has consistently linked reactive aggression with displays of anger and difficulty inhibiting anger responses throughout development, with early childhood, middle childhood, and adolescent samples all demonstrating a link (de Castro et al., 2005; Hubbard et 
al., 2002, 2004; Marsee \& Frick, 2007; Ostrov et al., 2013). However, many of the studies that assess emotion regulation/dysregulation in relation to reactive aggression, often also assess anger as a separate construct, but do not investigate dysregulated anger specifically (e.g., Calvete \& Orue, 2012; Marsee \& Frick, 2007; Ostrov et al., 2013). Therefore, the specific influence of anger dysregulation on the links between affective empathy and reactive aggression merits further investigation. In the current study, we expect associations between empathy and reactive aggression to be most evident at high levels of anger dysregulation.

Regarding the bidirectional associations between affective empathy and proactive aggression, if and how anger dysregulation plays a role within these links is harder to determine. Unlike reactive aggression, research on the associations with proactive aggression and anger or anger dysregulation are inconsistent, which is perhaps due to the heterogeneity of measures used to assess this construct (e.g., Marsee \& Frick, 2007; Ostrov et al., 2013; Pouw et al., 2013). While some research in middle childhood through adolescence has found that proactive aggression is not uniquely associated with anger (de Castro et al., 2005; Hubbard et al., 2002, 2004; Marsee \& Frick, 2007), other research in early childhood and mixed middle childhood and adolescent samples do demonstrate that these two constructs covary (e.g., Ostrov et al., 2013; Pouw et al., 2013). More specifically in a study of youth aged 9 to 15 years, Pouw and colleagues (2013) found a positive relationship between anger dysregulation and proactive aggression in both typically developing youth and youth with ASD. On the other hand, in a longitudinal study of youth aged 2 to 4 years old, Ostrov and colleagues' (2013) found that while anger predicted increases in proactive aggression, proactive aggression also predicted decreases in anger. It is important to note that Ostrov and colleagues (2013) also found that proactive aggression and emotion regulation skills were positively bidirectionally associated with one 
another in 2 to 4 year olds, with both proactive aggression predicting increased emotion regulation and emotion regulation predicting increased proactive aggression. Ostrov and colleagues (2013) also note that the positive associations between proactive aggression and emotion regulation may indicate that youth may utilize advanced emotional knowledge to harm others. On one hand (if low anger dysregulation is indicative of youth who are skilled at emotion regulation) this suggests that proactively aggressive youth who are low in anger dysregulation may be especially skilled at controlling and repressing affective empathy over time. Conversely, this may also suggest that youth who do not demonstrate deficits in affective empathy and who are low in anger dysregulation might be able to regulate affective empathy related to specific victims and therefore mitigate the influence of general affective empathy which might have otherwise decreased proactive aggression (Eisenberg et al., 2010; Fernandez \& Marshall, 2003; Olweus, 1993; Smith \& Thompson, 1991). Thus, the moderating role of anger dysregulation within the links between affective empathy and proactive aggression were evaluated, but no specific hypotheses were posited.

\section{The Current Study}

In sum, the current study examines the reciprocal associations between empathy and proactive and reactive aggression and how emotion regulation may moderate these relationships in a middle childhood sample at two time points, six months apart. Examining these associations in middle childhood is important, as it may be a critical period for development of both empathic and aggressive tendencies (Eisenberg et al., 2010; Eisenberg et al., 1991; Piquero et al., 2012). Moreover, evaluating these associations over a 6-month period allows for an examination of the reciprocal influence of empathy and proactive and reactive aggression, while staying within this developmental period. 
We expected to find bidirectional associations between affective empathy and proactive aggression, such that low levels of affective empathy at time 1 were associated with high levels of proactive aggression at time 2 and high proactive aggression at time 1 were associated with low levels of affective empathy at time 2 . Regarding the influence of anger dysregulation, we were unsure if and how anger dysregulation would moderate the associations between affective empathy and proactive aggression due to the mixed research on how proactive aggression, emotion regulation, and anger are linked (e.g., Ostrov et al., 2013; Pouw et al., 2013).

We expected high levels of affective empathy to predict high levels of reactive aggression. In contrast, high levels of reactive aggression at time 1 could be associated with low levels of affective empathy at time 2; however, this association is not as well established. Finally, associations between affective empathy and reactive aggression were expected to be most evident at high levels of anger dysregulation.

\section{Methods}

Participants included 294 elementary school children (52\% female), in grades third through fifth $(M=3.96, S D=.835)$ and their primary classroom teachers $(\mathrm{n}=17)$. The study utilized previously collected data from a rural elementary school in the Midwestern United States. Students were eligible to participate in the study if they were in third, fourth, or fifth grade, enrolled in the school at both time points, and were not receiving any special education services. Approximately $76 \%$ of the eligible students participated in the study. Data was collected in fall 2014 (time 1) and spring 2015 (time 2). School records data indicated that approximately $40 \%$ of students received free or reduced-price lunch and approximately $90.9 \%$ of students identified as Caucasian. Further, the community in which the school was located had an 
average per capita income of $\$ 25,369$, with $5 \%$ of individuals living below the federal poverty line, and the primary language spoken at home was English (U. S. Census Bureau, 2010).

\section{Measures}

Affective Empathy. Children self-reported on a 6-item questionnaire to assess for affective empathy (e.g., "When I see someone being picked on, I feel kind of sorry for them"; Davis, 1980; Eisenberg et al., 1991; Spinrad et al., 1999). The scale asks children to report on a three-point response scale $(1=$ Not like you and $3=$ Really like you $)$. The measure is a version of the Empathic Concern subscale from the Interpersonal Reactivity Index (IRI; Davis, 1980) which was adapted for use in children (Eisenberg et al., 1991; Spinrad et al., 1999). Davis (1980) established internal reliability (i.e., homogeneity) and test-retest reliability. Internal consistency in the current study was acceptable at both time points $(\alpha=.73-.78)$, which replicates past research (Eisenberg et al., 1991; Spinrad et al., 1999). Face validity has also been established for this measure, as the measure assesses the tendency for children to feel emotions for others and asks explicit questions about these tendencies (Davis, 1980; Spinrad et al., 1999).

Anger Dysregulation. Children self-reported on the 11-item Children's Anger Management Scale (CAMS; Zeman, Shipman, \& Suveg, 2002), which was originally adapted from the Children's Sadness Management Scale (Zeman et al., 2001). The anger scale has demonstrated three subscales via factor analysis, which assess inhibition, emotion coping, and dysregulation (Zeman et al., 2001; Zeman et al., 2002). Given the research interest of the current study and consistent with previous literature, mean scores on the dysregulation subscale were used to assess for anger dysregulation (e.g., Houltberg, Morris, Cui, Henry, \& Criss, 2014; McAuliffe, Hubbard, Rubin, Morrow, \& Dearing, 2006). The dysregulation subscale is comprised of three items which ask children to report on a 3-point Likert scale $(1=$ Hardly-ever, 
2 = Sometimes, 3 = Often) about how they typically behave when they are feeling mad (e.g., "I do things like slam doors when I am mad"). While the CAMS scale was originally validated in a population of middle childhood boys (Zeman et al., 2002), it has since been used with both sexes (e.g., Houltberg et al., 2014). Previous research has demonstrated that both internal consistency and test-retest reliability of the subscale are acceptable to good (McAuliffe et al., 2006; Zeman et al., 2002). In line with these previous findings, in the current sample, internal consistency was modest $(\alpha=.65)$. Additionally, comparisons with the Emotion Regulation Checklist and the Child Behavior Checklist have established construct validity of the CAMS (Suveg \& Zeman, 2004; Shields \& Cicchetti, 1997; Zeman et al., 2002). Finally, predictive validity has been established in past research as high scores on the dysregulation subscale predicted increased internalizing symptoms (Zeman et al., 2002).

Proactive and Reactive Aggression. Teachers completed the 6-item Proactive/Reactive Aggression Scale (PRA; Dodge \& Coie, 1987) using a 5-point scale $(1=$ Never and $5=$ Almost always). Three items on the scale assess for proactive aggression (e.g., "Gets other kids to gang up on somebody that he/she does not like") and three items assess for reactive aggression (e.g., "Feels that other children are to blame in a fight and feels that they started the trouble"). While the scale was originally developed for use in boys, PRA has since been used to assess aggression in both sexes and has demonstrated good internal reliability (e.g., Fite, Evans, Pederson, \& Tampke, 2017). Dodge and Coie (1987) established internal reliability (i.e., homogeneity) with high intra and inter-scale correlations. In the current study internal consistencies were good at time 1 and time 2 for both proactive and reactive aggression $(\alpha=.78-.85$ and $\alpha=.93-.95$, respectively), replicating past research (Connor, Steingard, Anderson, \& Melloni Jr., 2003; Fite et al., 2017). Construct, concurrent, and content validity were established in Dodge and Coie's 
(1987) study through their assessment of internal consistency and factor structure of the measure, as well as their comparison to other related behavioral patterns. Predictive validity has been established in past research as high scores on the measure scale predicted expected contingencies (e.g., poor social skills and delinquency; McAuliffe et al., 2006; Smithmyer, Hubbard, \& Simons, 2000).

\section{Procedure}

The researchers' institutional review board and the elementary school's administrators approved all study procedures prior to study commencement. All parents/caregivers at the school were given informational letters and consent forms for their children's participation in student back-to-school packets. Teachers were informed of the study and its purpose at school staff meetings and given the opportunity to consent to participate. Study staff emphasized that participation in the study was optional and lack of participation would not negatively impact them in any way.

Teacher and student data were collected at two time points: November 2014 (time 1) and April 2015 (time 2). Researchers waited two months after the start of the school year before collecting time 1 data to allow teachers to get acquainted with students (Fite et al., 2017).

Student data collection occurred in the child's classroom in a group setting throughout the course of one 30-minute session per classroom. Verbal assent was obtained prior to each data collection session. Teachers, children who lacked parental consent, and children who denied assent were removed from classrooms before data collection. Participating students were given individual study packets and were encouraged to complete the packet as a research assistant read the measures aloud, so students were not limited in participation by reading comprehension levels. As one research assistant read aloud, two to three other research assistants walked around 
the classroom to answer any questions that students may have had and discourage disruptive behavior. Children received pencils for their participation.

Data from consenting teachers were collected online within two weeks of each student data collection. In addition to a paper instruction packet, teachers were also emailed instructions with a link to the online survey, which took about 10 minutes to complete per student. Teachers reported on 17-24 students per class. Teachers were paid $\$ 50$ for completing measures on all of the students in their classroom and $\$ 25$ if they completed measures on only a portion of their students.

\section{Data Analysis}

Data were analyzed via path models, utilizing a panel design with autoregressive and cross-lagged paths via Mplus software (Muthén \& Muthén, 2001). Grade and gender were also included as covariates in the models, as grade and gender differences in aggression and empathy have been found (Dadds et al., 2008; Jolliffe \& Farrington 2006; Lovett \& Sheffield, 2007; Rieffe et al., 2016; Salmivalli \& Nieminen, 2002). All variables were standardized before conducting analyses to aid in the interpretation of interaction effects and reduce concerns of multicollinearity (Marquardt, 1980). Skewness and kurtosis of all variables at time 2 fell within the recommended range of values by Kline (2011) for maximum likelihood estimation, with proactive aggression skewness of 2.454 and kurtosis of 5.527, reactive aggression skewness of 1.898 and kurtosis of 3.059, and empathy skewness of -1.462 and kurtosis of 2.421 .

Specifically, Full Information Maximum Likelihood Estimation (FIMLE) was used to analyze data, which accommodated missing data. All model parameters were calculated at once (i.e., means, intercepts, covariants, and path coefficients; Kline, 2011). It is important to note that this approach assumes that data are missing at random, which can be difficult to evaluate or 
determine (Arbuckle, 1996). In order to assess if data in the current sample were missing at random, participants without missing data were compared to participants with missing data at time 2 and the groups were evaluated for significant differences (Fite, Colder, Lochman, \& Wells, 2006). A series of independent samples t-tests revealed that there were significant differences between those who completed a survey at time 2 and those who did not, with reactive $(\mathrm{t}(292)=2.697, p=.007)$ and proactive aggression $(\mathrm{t}(292)=3.07, p=.002)$ scores significantly higher for individuals who did not complete the survey at time 2. It should be noted that the number of individuals with missing data at time 2 was small $(n=4)$ and that FIMLE has still been found to be more efficient and less biased than other missing data techniques, such as pairwise and listwise deletion, even when data are not missing at random (Arbuckle, 1996; Kline, 2011). Cross-lagged relationships were assessed between empathy, proactive aggression, and reactive aggression (Figure 1). In subsequent models (Figure 2) anger dysregulation was evaluated as a moderator of associations. Note that interaction effects were evaluated one at a time due to power considerations.

Estimated models were fully saturated, with no degrees of freedom; therefore, goodnessof-fit indices are not reported. Finally, note that according to Aiken and West's (1991) power tables the study has power to detect medium to large interaction effects at the current sample size.

\section{Results}

Descriptive Statistics. Descriptive statistics, including means, ranges, standard deviations, skewness, and kurtosis, as well as bivariate correlations between study variables, are presented in Table 1 . Gender was negatively correlated with time 1 reactive aggression $(r=-.20$, $p=.001)$, time 2 reactive aggression $(r=-.22, p<.001)$, and time 2 proactive $(r=-.14, p=.02)$ 
and positively correlated with time 2 empathy $(r=.21, p<.001)$, such that boys demonstrated higher levels of proactive and reactive aggression and girls demonstrated higher levels of empathy. Grade was positively correlated with time 1 empathy $(r=.17, p=.003)$, such that older children demonstrated higher levels of empathy. Reactive and proactive aggression were positively correlated with each other at time $1(r=.70, p<.001)$ and time $2(r=.65, p<.001)$. Additionally, time 1 reactive aggression was positively correlated with time 2 reactive $(r=.74, p$ $<.001)$ and proactive $(r=.49, p<.001)$ aggression; and time 1 proactive aggression was positively correlated with time 2 reactive $(r=.51, p<.001)$ and proactive $(r=.62, p<.001)$ aggression. Time 1 empathy was significantly correlated with time 2 empathy $(r=.49, p<.001)$. Time 1 empathy was not significantly correlated with time 1 proactive aggression $(r=-.03, p=$ $.60)$, time 1 reactive aggression $(r=-.01, p=.87)$, time 2 proactive aggression $(r=-.09, p=.12)$, nor time 2 reactive aggression $(r=-.04, p=.55)$. However, time 2 empathy was significantly correlated with time 2 proactive aggression $(r=-0.12, p=.04)$, but not time 2 reactive $\operatorname{aggression}(r=-.11, p=.08)$.

First order effects. A first order effect path model was estimated to examine the associations between proactive aggression, reactive aggression, and empathy over time (Model 1 depicted in Figure 1). Neither control variable (i.e., gender nor grade) predicted time 2 proactive aggression $(\beta=-.05, \mathrm{SE}=.05, p=.33$ and $\beta=.07, \mathrm{SE}=.05, p=.14)$ nor reactive aggression $(\beta$ $=-.06, \mathrm{SE}=.04, p=.12$ and $\beta=-.01, \mathrm{SE}=.04, p=.90)$. Gender significantly positively predicted empathy at time $2(\beta=.13, \mathrm{SE}=.05, p=.009)$ such that girls were more empathetic than boys, but grade did not $(\beta=-.07, \mathrm{SE}=.05, p=.17)$. Proactive aggression, reactive aggression, and empathy all demonstrated stability across time, with time 1 proactive aggression significantly predicting time 2 proactive aggression $(\beta=0.55, \mathrm{SE}=0.06, p<.001)$, time 1 
reactive aggression predicting time 2 reactive aggression $(\beta=0.74, \mathrm{SE}=0.06, p<.001)$, and time 1 empathy predicting time 2 empathy $(\beta=0.49, \mathrm{SE}=0.05, p<.001)$.

As predicted, time 1 empathy significantly negatively predicted time 2 proactive aggression $(\beta=-0.10, \mathrm{SE}=.05, p=.04)$. In contrast to expectations, time 1 proactive aggression trended towards positively predicting time 2 empathy $(\beta=0.14, \mathrm{SE}=0.07, p=0.057)$. Time 1 empathy did not significantly predict time 2 reactive aggression $(\beta=-0.03, \mathrm{SE}=0.04, p=0.4)$. However, time 1 reactive aggression significantly negatively predicted time 2 empathy ( $\beta=-$ $0.17, \mathrm{SE}=.0 .07, p=0.02$ ). Time 1 Reactive aggression was a marginally significant positive predictor of time 2 proactive aggression $(\beta=0.11, \mathrm{SE}=0.06, p=0.09)$, but time 1 proactive aggression did not significantly predict time 2 reactive aggression $(\beta=-0.002, \mathrm{SE}=0.06, p=$ .97).

Anger dysregulation moderation. Next, three multiplicative interaction terms were added one at a time to model 1 in order to examine the potential interaction effects between anger dysregulation and proactive aggression, reactive aggression, and empathy on subsequent outcomes. However, no significant interactions emerged $(\beta s=-.02-.04, p s=0.28-0.84){ }^{1}$

\section{Discussion}

The current study utilized a short-term longitudinal design to examine the potential bidirectional associations between affective empathy with proactive and reactive aggression. The role that anger dysregulation may play in these links was also evaluated. This study significantly advances previous work on aggression and empathy by examining the unique functions of

\footnotetext{
${ }^{1}$ As follow-up exploratory analyses, gender was also evaluated as a moderator of these effects using a multiple group model approach. Results indicated that constraining effects to be equal across genders did not result in a significant decrement in model fit for first order effects $\left(\chi^{2}(2)=2.275-4.741\right.$, $\left.p s=.093-.32\right)$ or interaction effects $\left(\chi^{2}(4)=2.856-6.120, p s=0.19-0.582\right)$. Note, however, due to power considerations no further conclusions should be drawn.
} 
aggression, evaluating bidirectional effects over a 6 month period, and utilizing an understudied population (i.e., youth in middle childhood).

As predicted, empathy at time 1 significantly negatively predicted proactive aggression at time 2. This finding supports our conceptualization that high levels of affective empathy would result in youth inhibiting proactive aggression (Bandura, 1973; Deschamps et al., 2018; Ostrov et al., 2013; Stavrinides et al., 2010). This finding also aligns with previous cross-sectional and longitudinal research demonstrating a negative relationship between affective and emotional empathy and proactive aggression in youth ranging from 6 to 18 years old (Deschamps et al., 2018; Espelage et al., 2004; Euler et al., 2017; Stavrinides et al., 2010) as well as research demonstrating CU traits (which include a lack of empathy) positively predict proactive aggression in 14 to 18 year old youth (Orue et al., 2016).

However, in contrast to expectations, proactive aggression at time 1 trended towards positively predicting empathy at time 2 . This finding does not support the BAS/BIS model of aggressive behavior (Beaver et al., 2008; Gray, 1972; Harmon-Jones \& Peterson, 2008; Smits \& Kuppens, 2005) in which we proposed the salience of the reward of aggressive behavior would motivate youth to further reduce potentially punishing feelings of affective empathy over time. Moreover, this result contradicts findings from the only other longitudinal study we were able to identify that examined the influence of proactive aggression on empathy over time in sixth grade youth (i.e., Stavrinides et al., 2010), as well as previous cross-sectional and retrospective research demonstrating a negative association between proactive aggression and empathy in fourth through sixth grade youth (Katsuma \& Yamasaki, 2008; Olweus, 1993). It should be noted that the year of data collection coincided with the elementary school's first year of implementation of a social-emotional curriculum, which included content focused on increasing 
socioemotional competence and, perhaps as a result of this intervention, mean levels of selfreported empathy in our sample increased from time 1 to time 2 . However, this increase in mean levels of affective empathy does not explain why proactive aggression uniquely predicted high affective empathy levels. Rather, the positive relationship between time 1 proactive aggression and time 2 empathy may be a result of the measure we used to assess affective empathy, which asked youth to report on their empathic feelings for other children in general, rather than on specific targets of their aggression. Past research has demonstrated that certain types of adult aggressors (i.e., rapists and sex offenders of children) lack empathy only for their specific victims, but do not demonstrate global empathy deficits (Brown, Walker, Gannon, \& Keown, 2013; Fernandez \& Marshall, 2003). Moreover, some research has found adult perpetrators of intimate partner violence and child sexual offenders actually experience high rates of emotional empathy but experience this empathy in a distressing way (Covell, Huss, \& LanghinrichsenRohling, 2007; Romero-Martínez, Lila, Sariñana-González, González-Bono, \& Moya-Albiol, 2013). Additionally, past work has demonstrated that proactive aggression is positively associated with increased social and emotional intelligence (Björkqvist, Österman, \& Kaukiainen, 2000; Ostrov et al., 2013) as well as cognitive empathy (Sutton, Smith, \& Swettenham, 1999). Therefore, it could be that proactively aggressive youth in our sample were particularly receptive to the social-emotional curriculum at school and were able to use this advanced knowledge repress or control feelings of empathy for their specific victims while still increasing their general affective empathy (and potentially using this advanced knowledge to harm other youth; Carpenter \& Nangle, 2006; Hawley, 2003; Sutton et al., 1999). Indeed, past research has shown that interventions which focus on increasing general affective empathy in adult aggressors may not be effective (Day, Casey, \& Gerace, 2010), while other interventions 
for school age youth targeted at increasing empathy specifically for an individual's victims show more promising results (Garandeau, Vartio, Poskiparta, \& Salmivalli, 2016). Alternatively, it could be that the curriculum increased empathy among proactively aggressive youth that may results in less proactive aggression in the future. However, future research in additional waves of data are needed to evaluate this.

As predicted, high levels of reactive aggression predicted low levels of affective empathy. This result supports our theory that reactively aggressive youth may adopt universally negative perceptions of their peers (Dodge, 2006) and therefore experience a decline in affective empathy over time. As mentioned previously, research on the impact of reactive aggression on empathy is extremely limited and thus only one previous study was identified (i.e., Katsuma \& Yamasaki, 2008), which indicated that reactive aggression did not have an impact on affective empathy in youth in fourth through sixth grade. Therefore, current findings represent an important contribution to the literature.

Contrary to our predictions, however, time 1 affective empathy was not significantly positively associated with time 2 reactive aggression. Based on work suggesting that unpleasantness of an experience increases the probability of engaging in reactive aggression (Berkowitz, 1993), we had originally proposed that experiencing affective empathy aversively (i.e., via personal distress or with negative emotions such as sadness or anger) would lead individuals to be more likely to engage in reactive aggression. However, our theory that affective empathy would lead to an overall greater emotional arousal and lead to more reactive aggression was not supported. While previous research on affective empathy and reactive aggression is mixed (Euler et al., 2017; Lovett \& Sheffield, 2007; Pouw et al., 2013), our null findings align 
with Euler and colleagues (2017) who demonstrated that affective empathy was not associated with reactive aggression in a sample of highly aggressive adolescents (aged 12 to 18 years).

Finally, anger dysregulation did not moderate any bidirectional associations between affective empathy and proactive or reactive aggression. Most notably, results regarding the role of anger dysregulation in associations between affective empathy and reactive aggression were not consistent with hypotheses. We had expected that youth who experienced affective empathy along with anger dysregulation would be more primed to engage in reactive aggression because they would experience empathy more aversively (Anderson \& Bushman, 2002; Berkowitz, 1993; Eisenberg et al., 2010). Additionally, we had expected that youth who experienced high levels of reactive aggression alongside anger dysregulation would experience even lower levels of affective empathy due to increased negative affect and negative perceptions of peers via maladaptive SIP (Dodge, 2006). Current findings suggest that anger dysregulation may not be closely related to affective empathy or, at least, does not significantly contribute to experiencing affective empathy aversively that results in a link with reactive aggression in this age group. Alternatively, our null findings could also be the result of limitations in our measurement of anger dysregulation in the current study, which relied on children's self-report of their anger on only three items. Other studies that have found significant effects with anger and reactive aggression in youth (i.e., aged 2 to 7 years old) have relied on teacher reports of children's angry behavior or physiological measures (e.g., Hubbard et al., 2004; Ostrov et al., 2013). We were unsure how anger dysregulation would influence the bidirectional associations between affective empathy and proactive aggression, given mixed research on how emotion regulation and anger interact with proactive aggression and/or empathy in youth (de Castro et al. 2005; Hubbard et al., 2002, 2004; Marsee \& Frick, 2007; Ostrov et al., 2013; Pouw et al., 2013). Current null findings 
regarding the moderating role of anger dysregulation in associations between proactive aggression and affective empathy align with past research demonstrating a null relationship between anger and proactive aggression in studies with youth ranging from 2 to 18 years old (de Castro et al., 2005; Hubbard et al., 2002, 2004; Marsee \& Frick, 2007).

The current study has several strengths, including multiple informants and a longitudinal design; however, several limitations should be acknowledged. Firstly, the internal consistency for our measure of anger dysregulation was modest $(\alpha=.65)$ and relied on children's self-report of their anger. Future research would benefit from utilizing a measure with a higher internal consistency as well as gathering information from parent and/or teacher informants (who may have a better idea of how a child actually acts when they are angry) or using physiological measures (e.g., Hubbard et al., 2004; Ostrov et al., 2013). Additionally, combining different measures of empathy (such as behavioral observations, parent-report, or teacher-report) with child self-reports of empathy and measuring empathy towards specific victims may benefit future studies and allow for a more refined conceptualization of the associations between empathy and aggression (e.g. Deschamps et al., 2018). Future research may also benefit from examining forms (i.e., physical and relational) as well as functions (i.e., proactive and reactive) of aggression, as work suggests that empathy may interact differently with combinations of forms and functions of aggression (e.g., proactive physical aggression verses proactive relational aggression; Björkqvist et al., 2000). Additionally, further work could also benefit from studying the constructs of empathy and aggression over multiple academic years. Moreover, the current sample utilized a population in rural, midwestern United States that lacked ethnic and racial diversity, therefore generalizability of results may be limited. Finally, the sample of the current study $(n=294)$ only had power to detect medium to large, not small, effects (Aiken \& West, 1991). Additional 
exploratory analyses of gender differences were nonsignificant. However, more research using large sample sizes with power to detect small effects are needed to confirm this null effect.

Findings from the current study have several important clinical implications. The findings that high levels of empathy predicted decreases in proactive aggression, but high levels of proactive aggression predicted increases in empathy, suggests that there are different implications in utilizing empathy as a component for prevention verses intervention programs for aggression. These results suggest that global empathy training may be beneficial in preventing aggressive behavior for youth who are not yet exhibiting proactively aggressive tendencies. However, empathy training may not be effective for youth who are already engaging in proactive aggression, unless perhaps increases in empathy are targeted specifically at the victims they aggressed against (Day et al., 2010; Garandeau et al., 2016; McMahon \& Washburn, 2003). Given that stable inverse associations between proactive aggression and empathy first start to emerge in in middle childhood (Lovett \& Sheffield, 2007), empathy training for aggression prevention may be most effective for youth in early childhood. Results concerning reactive aggression, in which high levels of reactive aggression predicted low levels of affective empathy, but affective empathy did not impact reactive aggression, suggest that empathy may not be a salient construct to target for prevention of reactive aggression. However, empathy may be an important component to target in interventions for youth already engaging in reactive aggression, especially given the proposed theory that reactive aggression develops because of maladaptive SIP and may lead to and be reinforced by universally negative perceptions of peers (Dodge, 2006). Alternatively, given the complex associations empathy demonstrates with aggressive behavior, some researchers have proposed that compassion (i.e., "valuing other people and caring about their welfare but without necessarily feeling their pain") is a better construct to 
target for interventions (Bloom, 2017) and may be more appropriate for a middle childhood sample. Future research on empathy training as a treatment component for proactively and reactively aggressive youth may benefit from examining the role of developmental timing as well as type of intervention.

\section{References}

Aiken, L. S., \& West, S. G. (1991). Multiple Regression: Testing and Interpreting Interactions. Thousand Oaks, CA. Sage Publications, Inc.

Anderson, C. A., \& Bushman, B. J. (2002). Human aggression. Annual Review of Psychology, $53,27-51$.

Arbuckle, J. L. (1996). Full information estimation in the presence of incomplete data. In G. A. Marcoulides \& R.E. Shumaker (Eds.), Advanced Structural Equation Modeling: Issues and Techniques (pp. 243-277). Mahwah, NJ: Erlbaum.

Bandura, A. (1973). Aggression: a social learning analysis. Englewood Cliffs, NJ: Prentice Hall.

Bandura, A. (1983). Psychological mechanisms of aggression. In R. G. Green \& E. I. Donnerstein (Eds.), Aggression: theoretical and empirical views (pp. 1-40). New York: Academic.

Batson, C. D. (1991). The altruism question: toward a social-psychological answer. Hillsdale, NJ: Erlbaum.

Beaver, J. D., Lawrence, A. D., Passamonti, L., \& Calder, A. J. (2008). Appetitive motivation predicts the neural response to facial signals of aggression. Journal of Neuroscience, 28(11), 2719-2725. 
Berkowitz, L. (1993). Aggression: Its causes, consequences, and control. New York: McGraw Hill.

Björkqvist, K., Österman, K., \& Kaukiainen, A. (2000). Social intelligence - empathy= aggression? Aggression and Violent Behavior, 5(2), 191-200.

Bloom, P. (2017). Empathy and its discontents. Trends in Cognitive Sciences, 21(1), 24-31.

Brown, S. J., Walker, K., Gannon, T. A., \& Keown, K. (2013). Creating a psychologically comfortable position: The link between empathy and cognitions in sex offenders. Journal of Sexual Aggression, 19(3), 275-294.

Calvete, E., \& Orue, I. (2012). The role of emotion regulation in the predictive association between social information processing and aggressive behavior in adolescents. International Journal of Behavioral Development, 36(5), 338-347.

Carlo, G., Mestre, M. V., Samper, P., Tur, A., \& Armenta, B. E. (2010). Feelings or cognitions? Moral cognitions and emotions as longitudinal predictors of prosocial and aggressive behaviors. Personality and Individual Differences, 48(8), 872-877.

Carpenter, E. M., \& Nangle, D. W. (2006). Caught between stages: Relational aggression emerging as a developmental advance in at-risk preschoolers. Journal of Research in Childhood Education, 21(2), 177-188.

Choe, D. E., Shaw, D. S., \& Forbes, E. E. (2015). Maladaptive social information processing in childhood predicts young men's atypical amygdala reactivity to threat. Journal of Child Psychology and Psychiatry, 56(5), 549-557.

Connor, D. F., Steingard, R. J., Anderson, J. J., \& Melloni Jr., R. H. (2003). Gender differences in reactive and proactive aggression. Child Psychiatry and Human Development, 33(4), 279-294. 
Cooley, J. L., \& Fite, P. J. (2016). Peer victimization and forms of aggression during middle childhood: The role of emotion regulation. Journal of Abnormal Child Psychology, 44(3), 535-546.

Covell, C. N., Huss, M. T., \& Langhinrichsen-Rohling, J. (2007). Empathic deficits among male batterers: A multidimensional approach. Journal of Family Violence, 22(3), 165-174.

Crick, N.R., \& Dodge, D.A. (1994). A review and reformulation of social informationprocessing mechanisms in children's social adjustment. Psychological Bulletin, 115(1), 74-101.

Crick, N.R., \& Dodge, D.A. (1996). Social information-processing mechanisms in reactive and proactive aggression. Child Development, 67(3), 993-1002.

Dadds, M. R., Hunter, K., Hawes, D. J., Frost, A. D., Vassallo, S., Bunn, P., ... \& El Masry, Y. (2008). A measure of cognitive and affective empathy in children using parent ratings. Child Psychiatry and Human Development, 39(2), 111-122.

Davis, M. H. (1980). A multidimensional approach to individual differences in empathy. JSAS Catalog of Selected Documents in Psychology, 10, 2-19.

Davis, M. H. (1983). Measuring individual differences in empathy: Evidence for a multidimensional approach. Journal of Personality and Social Psychology, 44(1), 113126.

Day, A., Casey, S., \& Gerace, A. (2010). Interventions to improve empathy awareness in sexual and violent offenders: Conceptual, empirical, and clinical issues. Aggression and Violent Behavior, 15(3), 201-208.

de Castro, B. O., Merk, W., Koops, W., Veerman, J. W., \& Bosch, J. D. (2005). Emotions in 
social information processing and their relations with reactive and proactive aggression in referred aggressive boys. Journal of Clinical Child and Adolescent Psychology, 34(1), $105-116$

Decety, J. E., \& Ickes, W. E. (2009). The Social Neuroscience of Empathy. MIT Press.

Decety, J., \& Jackson, P. L. (2004). The functional architecture of human empathy. Behavioral and Cognitive Neuroscience Reviews, 3(2), 71-100.

Decety, J., \& Moriguchi, Y. (2007). The empathic brain and its dysfunction in psychiatric populations: Implications for intervention across different clinical conditions. BioPsychoSocial Medicine, 1(1), 1-22.

Deschamps, P. K., Verhulp, E. E., de Castro, B. O., \& Matthys, W. (2018). Proactive aggression in early school-aged children with externalizing behavior problems: A longitudinal study on the influence of empathy in response to distress. American Journal of Orthopsychiatry, 88(3), 346-353.

Dodge, K. A. (1980). Social cognition and children's aggressive behavior. Child Development, 51(1), 162-170.

Dodge, K. A. (2006). Translational science in action: Hostile attributional style and the development of aggressive behavior problems. Development and Psychopathology, $18(3), 791-814$.

Dodge, K. A., \& Coie, J. D. (1987). Social information-processing factors in reactive and proactive aggression in children's peer groups. Journal of Personality and Social Psychology, 53(6), 1146-1158.

Eisenberg, N., \& Eggum, N. D. (2009). Empathic responding: Sympathy and personal distress. 
In J. Decety \& W. Ickes (Eds.), The social neuroscience of empathy (pp. 71-83).

Cambridge, MA: MIT Press.

Eisenberg, N., Eggum, N. D., \& Di Giunta, L. (2010). Empathy-related responding: Associations with prosocial behavior, aggression, and intergroup relations. Social Issues and Policy Review, 4(1), 143-180.

Eisenberg, N., Fabes, R. A., Schaller, M., Carlo, G., \& Miller, P. A. (1991). The relations of parental characteristics and practices to children's vicarious emotional responding. Child Development, 62(6), 1393-1408.

Eisenberg, N., Fabes, R. A., Shepard, S. A., Murphy, B. C., Jones, S., \& Guthrie, I. K. (1998). Contemporaneous and longitudinal prediction of children's sympathy from dispositional regulation and emotionality. Developmental Psychology, 34(5), 910.

Eisenberg, N., Fabes, R. A., \& Spinrad, T. L. (2006). Prosocial behavior. In N. Eisenberg (Vol. Ed.) and W. Damon \& R. M. Lerner (Series Eds.), Handbook of child psychology: Vol. 3. social, emotional, and personality development (6th ed., pp. 646-718). New York: Wiley.

Eisenberg, N., Shea, C. L., Carlo, G., \& Knight, G. (1991). Empathy-related responding and cognition: A "chicken and the egg" dilemma. In W. Kurtines \& J. Gewirtz (Eds.), Handbook of moral behavior and development. Vol. 2. research (pp. 63-88). Hillsdale, NJ: Erlbaum.

Espelage, D.L., Mebane, S.E., \& Adams, R.S. (2004). Empathy, caring, and bullying: Toward an understanding of complex associations. In D.L. Espelage \& S.M. Swearer (Eds.), Bullying in American schools: A social-ecological perspective on prevention and intervention (pp. 37-61). Mahwah, NJ: Erlbaum. 
Euler, F., Steinlin, C., \& Stadler, C. (2017). Distinct profiles of reactive and proactive aggression in adolescents: associations with cognitive and affective empathy. Child and Adolescent Psychiatry and Mental Health, 11(1), 1-14.

Fernandez, Y. M., \& Marshall, W. L. (2003). Victim empathy, social self-esteem, and psychopathy in rapists. Sexual Abuse: A Journal of Research and Treatment, 15(1), 1126.

Feshbach, N. D., \& Feshbach, S. (1969). The relationship between empathy and aggression in two age groups. Developmental Psychology, 1(2), 102-107.

Fite, P. J., Colder, C. R., Lochman, J. E., \& Wells, K. C. (2006). The mutual influence of parenting and boys' externalizing behavior problems. Journal of Applied Developmental Psychology, 27(2), 151-164.

Fite, P. J., Evans, S., Pederson, C., \& Tampke, E. C. (2017). Functions of aggression and disciplinary actions among elementary school age youth. Child \& Youth Care Forum, $46(6), 825-839$.

Frick, P. J., Cornell, A. H., Barry, C. T., Bodin, S. D., \& Dane, H. E. (2003). Callousunemotional traits and conduct problems in the prediction of conduct problem severity, aggression, and self-report of delinquency. Journal of Abnormal Child Psychology, 31(4), $457-470$.

Garandeau, C. F., Vartio, A., Poskiparta, E., \& Salmivalli, C. (2016). School bullies' intention to change behavior following teacher interventions: Effects of empathy arousal, condemning of bullying, and blaming of the perpetrator. Prevention science, 17(8), 10341043.

Gray, J. A. (1972). The psychology of fear and stress. McGraw-Hill, New York, NY. 
Harmon-Jones, E., \& Peterson, C. K. (2008). Effect of trait and state approach motivation on aggressive inclinations. Journal of Research in Personality, 42(5), 1381-1385.

Hawley, P. H. (2003). Strategies of control, aggression, and morality in preschoolers: An evolutionary perspective. Journal of Experimental Child Psychology, 85(3), 213-235.

Hosking, G., \& Walsh, I. (2005). The WAVE Report 2005: Violence and what to do about it. Croydon: Wave Trust.

Houltberg, B. J., Morris, A. S. , Cui, L., Henry, C. S., \& Criss, M. M. (2014). The role of youth anger in explaining links between parenting and early adolescent prosocial and antisocial behavior. The Journal of Early Adolescence, 36(3), 297-318.

Hubbard, J. A., Parker, E. H., Ramsden, S. R., Flanagan, K. D., Relyea, N., Dearing, K. F., ... \& Hyde, C. T. (2004). The relations among observational, physiological, and self-report measures of children's anger. Social Development, 13(1), 14-39.

Hubbard, J. A., Smithmyer, C. M., Ramsden, S. R., Parker, E. H., Flanagan, K. D., Dearing, K. F., ... \& Simons, R. F. (2002). Observational, physiological, and self-report measures of children's anger: Relations to reactive versus proactive aggression. Child Development, 73(4), 1101-1118.

Ickes, W.J. Empathic accuracy. New York: Guilford Press; 1997.

Jolliffe, D., \& Farrington, D. P. (2004). Empathy and offending: A systematic review and metaanalysis. Aggression and Violent Behavior, 9(5), 441-476.

Jolliffe, D., \& Farrington, D. P. (2006). Development and validation of the Basic Empathy Scale. Journal of Adolescence, 29(4), 589-611.

Katsuma, L., \& Yamasaki, K. (2008). The effects of three types of aggression on empathy in elementary school children. Japanese Journal of Psychology, 79(4), 325-332. 
Kline, R. B. (2011). Principles and Practice of Structural Equation Modeling (3rd ed.). New York: Guilford Press.

Konrath, S. H., O'Brien, E. H., \& Hsing, C. (2011). Changes in dispositional empathy in American college students over time: A meta-analysis. Personality and Social Psychology Review, 15(2), 180-198.

Kruh, I. P., Frick, P. J., \& Clements, C. B. (2005). Historical and personality correlates to the violence patterns of juveniles tried as adults. Criminal Justice and Behavior, 32(1), 6996.

Lorber, M. F., Del Vecchio, T., \& Slep, A. M. S. (2015). The emergence and evolution of infant externalizing behavior. Development and Psychopathology, 27(3), 663-680.

Lovett, B. J., \& Sheffield, R. A. (2007). Affective empathy deficits in aggressive children and adolescents: A critical review. Clinical Psychology Review, 27(1), 1-13.

Malti, T., Chaparro, M. P., Zuffianò, A., \& Colasante, T. (2016). School-based interventions to promote empathy-related responding in children and adolescents: A developmental analysis. Journal of Clinical Child \& Adolescent Psychology, 45(6), 718-731.

Marquardt, D. W. (1980). Comment: You should standardize the predictor variables in your regression models. Journal of the American Statistical Association, 75(369), 87-91.

Marsee, M. A., \& Frick, P. J. (2007). Exploring the cognitive and emotional correlates to proactive and reactive aggression in a sample of detained girls. Journal of Abnormal Child Psychology, 35(6), 969-981

McAuliffe, M. D., Hubbard, J. A., Rubin, R. M., Morrow, M. T., \& Dearing, K. F. (2006). Reactive and proactive aggression: Stability of constructs and relations to correlates. The Journal of Genetic Psychology, 167(4), 365-82. 
McMahon, S. D., \& Washburn, J. J. (2003). Violence prevention: An evaluation of program effects with urban African American students. The Journal of Primary Prevention, 24(1), 43-62.

Mehrabian, A., \& Epstein, N. (1972). A measure of emotional empathy. Journal of Personality, $40(4), 525-543$.

Muthén, L. K., \& Muthén, B. (2001). Mplus: The comprehensive modeling program for applied researchers. Los Angeles, CA: Muthén and Muthén.

Olweus, D. (1993). Bullying at school: What we know and what we can do. Oxford: Blackwell.

Orue, I., Calvete, E., \& Gamez-Guadix, M. (2016). Gender moderates the association between psychopathic traits and aggressive behavior in adolescents. Personality and Individual Differences, 94, 266-271.

Ostrov, J. M., Murray-Close, D., Godleski, S. A., \& Hart, E. J. (2013). Prospective associations between forms and functions of aggression and social and affective processes during early childhood. Journal of Experimental Child Psychology, 116(1), 19-36.

Pederson, C. A., Fite, P. J., \& Bortolato, M. (2017). The role of functions of aggression in associations between behavioral inhibition and activation and mental health outcomes. Journal of Aggression, Maltreatment \& Trauma, 27(8), 811-830.

Piquero, A. R., Carriaga, M. L., Diamond, B., Kazemian, L., \& Farrington, D. P. (2012). Stability in aggression revisited. Aggression and Violent Behavior, 17(4), 365-372.

Pouw, L. B. C., Rieffe, C., Oosterveld, P., Huskens, B., \& Stockmann, L. (2013). Reactive/proactive aggression and affective/cognitive empathy in children with ASD. Research in Developmental Disabilities, 34(4), 1256-1266.

Rieffe, C., Broekhof, E., Kouwenberg, M., Faber, J., Tsutsui, M. M., \& Güroğlu, B. (2016). 
Disentangling proactive and reactive aggression in children using self-report. European Journal of Developmental Psychology, 13(4), 439-451.

Romero-Martínez, Á., Lila, M., Sariñana-González, P., González-Bono, E., \& Moya-Albiol, L. (2013). High testosterone levels and sensitivity to acute stress in perpetrators of domestic violence with low cognitive flexibility and impairments in their emotional decoding process: A preliminary study. Aggressive Behavior, 39(5), 355-369.

Saarni, C. (1999). The development of emotional competence. New York: Guilford.

Salmivalli, C., \& Nieminen, E. (2002). Proactive and reactive aggression among school bullies, victims, and bully-victims. Aggressive Behavior: Official Journal of the International Society for Research on Aggression, 28(1), 30-44.

Shields, A., \& Cicchetti, D. (1997). Emotion regulation among school-age children: The development and validation of a new criterion Q-sort scale. Developmental Psychology, 33(6), 906-916.

Smith, P.K., \& Thompson, D. (1991). Practical approaches to bullying. London: David Foulton Publishers.

Smithmyer, C. M., Hubbard, J. A., \& Simons, R. F. (2000). Proactive and reactive aggression in delinquent adolescents: Relations to aggression outcome expectancies. Journal of Clinical Child Psychology, 29(1), 86-93.

Smits, D. J. M., \& Kuppens, P. (2005). The relations between anger, coping with anger, and aggression, and the BIS/BAS system. Personality and Individual Differences, 39(4), 783793.

Spinrad, T. L., Losoya, S. H., Eisenberg, N., Fabes, R. A., Shepard, S. A., Cumberland, A., ... \& 
Murphy, B. C. (1999). The relations of parental affect and encouragement to children's moral emotions and behaviour. Journal of Moral Education, 28(3), 323-337.

Stavrinides, P., Georgiou, S., \& Theofanous, V. (2010). Bullying and empathy: a short-term longitudinal investigation. Educational Psychology, 30(7), 793-802.

Sutton, J., Smith, P. K., \& Swettenham, J. (1999). Social cognition and bullying: Social inadequacy or skilled manipulation? British Journal of Developmental Psychology, 17(3), 435-450.

Suveg, C., \& Zeman, J. (2004). Emotion regulation in children with anxiety disorders. Journal of Clinical Child and Adolescent Psychology, 33(4), 750-759.

Thompson, R. A. (1994). Emotion regulation: a theme in search of definition. Monographs for the Society for Research in Child Development, 59(2-3), 25-52.

Thompson, R. A., Lewis, M., \& Calkins, S. D. (2008). Reassessing emotion regulation. Child Development Perspectives, 2(3), 124-131.

U. S. Census Bureau. (2010). State and County QuickFacts. Retrieved from http://quickfacts.census.gov

Zeman, J., Shipman, K., \& Penza-Clyve, S. (2001). Development and initial validation of the children's sadness management scale. Journal of Nonverbal Behavior, 25(3), 187-205.

Zeman, J., Shipman, K., \& Suveg, C. (2002). Anger and sadness regulation: Predictions to internalizing and externalizing symptomatology in children. Journal of Clinical Child and Adolescent Psychology, 31(3), 393-398. 


\section{Appendix}

Table 1. Correlations and descriptive statistics among Reactive Aggression, Proactive Aggression, and Empathy at times 1 and 2

\begin{tabular}{|c|c|c|c|c|c|c|c|c|}
\hline & 1 & 2 & 3 & 4 & 5 & 6 & 7 & 8 \\
\hline 1. Reactive & - & - & - & - & - & - & - & - \\
\hline \multicolumn{9}{|l|}{ Aggression T1 } \\
\hline 2. Proactive & $0.70 * *$ & - & - & - & - & - & - & - \\
\hline \multicolumn{9}{|l|}{ Aggression T1 } \\
\hline 3. Empathy $\mathrm{T} 1$ & -0.01 & -0.03 & - & - & - & - & - & - \\
\hline 4. Reactive & $0.74 * *$ & $0.51 * *$ & -0.04 & - & - & - & - & - \\
\hline \multicolumn{9}{|l|}{ Aggression T2 } \\
\hline 5. Proactive & $0.49 * *$ & $0.62 * *$ & -0.09 & $0.65^{* *}$ & - & - & - & - \\
\hline \multicolumn{9}{|l|}{ Aggression T2 } \\
\hline 6. Empathy T2 & -0.10 & 0.00 & $0.49 * *$ & -0.11 & $-0.12 *$ & - & - & - \\
\hline 7. Gender & $-0.20 * *$ & -0.11 & 0.10 & $-0.22 * *$ & $-0.14 *$ & $0.21 * *$ & - & - \\
\hline 8. Grade Level & -0.02 & 0.04 & $0.17 *$ & -0.02 & 0.08 & 0.02 & 0.00 & - \\
\hline $\mathrm{M}(S D)$ & $1.43(.80)$ & $1.18(.44)$ & $2.57(.44)$ & $1.53(.92)$ & $1.26(.58)$ & $2.96(.39)$ & $.52(.50)$ & $3.96(.83)$ \\
\hline Minimum & 1.00 & 1.00 & 1.33 & 1.00 & 1.00 & 1.24 & 0 & 3 \\
\hline Maximum & 5.00 & 3.33 & 3.00 & 5.00 & 4.00 & 3.40 & 1 & 5 \\
\hline Skewness & 2.04 & 2.68 & -1.02 & 1.90 & 2.45 & -1.46 & -0.07 & 0.08 \\
\hline Kurtosis & 3.63 & 6.90 & 0.26 & 3.06 & 5.53 & 2.42 & -2.00 & -1.55 \\
\hline
\end{tabular}

Note. $*=\mathrm{p}<.05$, two-tailed, $* *=\mathrm{p}<.001$, two-tailed; T1 $=$ Time $1, \mathrm{~T} 2 .=$ Time 2 
Figure 1. Bidirectional associations between time 1 and time 2 empathy, proactive aggression, and reactive aggression.

Time 1

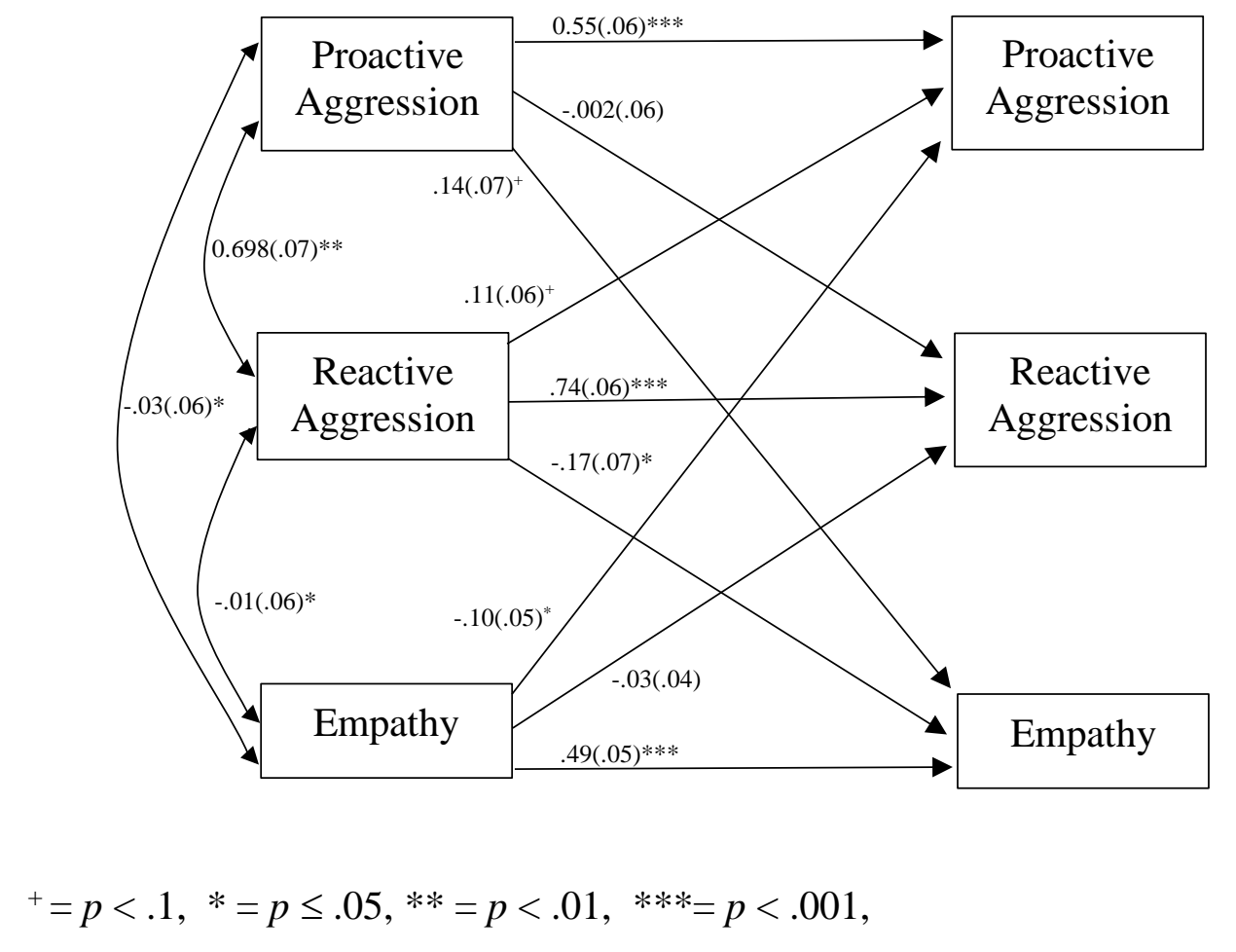

$+=p<.1, *=p \leq .05, * *=p<.01, * * *=p<.001$,

Time 2

Note. Standardized parameter estimates are reported outside parentheses and standard errors are reported inside parentheses. Gender and grade are estimated in the model, however are not included in figure for clarity. 
Figure 2. Proposed moderation of anger dysregulation on bidirectional associations between proactive aggression, reactive aggression, and empathy at times 1 and 2 .

Time 1

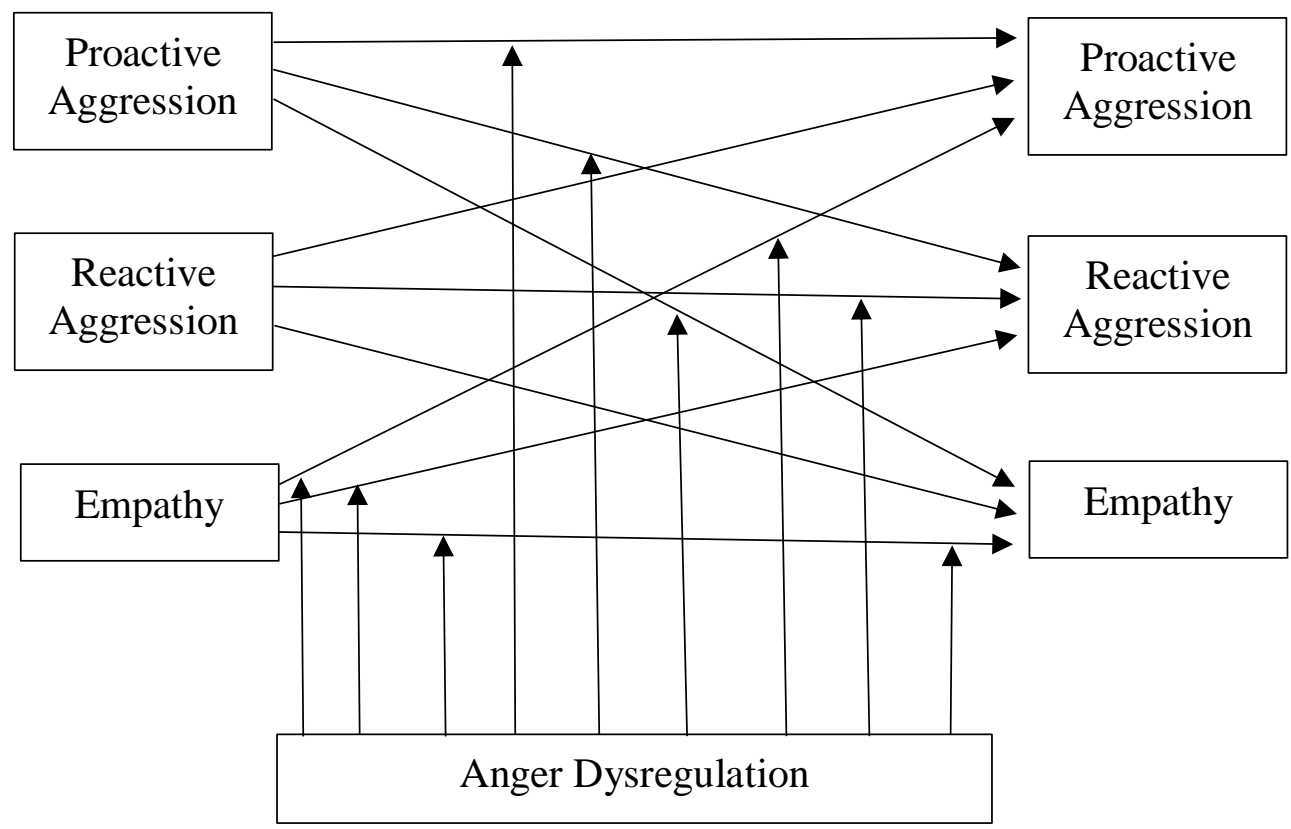

